Western University

Scholarship@Western

Department of Economics Research Reports

Economics Working Papers Archive

1971

\title{
Monopoly Theory in General Equilibrium and the Two-Sector Model of Economic Growth
}

Raveendra Batra

Follow this and additional works at: https://ir.lib.uwo.ca/economicsresrpt

Part of the Economics Commons

Citation of this paper:

Batra, Raveendra. "Monopoly Theory in General Equilibrium and the Two-Sector Model of Economic Growth." Department of Economics Research Reports, 7122. London, ON: Department of Economics, University of Western Ontario (1971). 
RESEARCH REPORT 7122

MONOPOLY THEORY IN GENERAL EQUILIBRIUM

AND THE TWO-SECTOR MODEL OF ECONOMIC GROWTH

by

Raveendra N. Batra 


\section{MONOPOLY THEORY IN GENERAL EQUIIIBRIUM AND THE}

TWO-SECTOR MODEL OF ECONOMIC GROWTH*

In the past decade, the two-sector growth model has received a good deal of attention from the growth theorist. ${ }^{1}$ One of the central assumptions of this model (and growth models in general) is that all markets are characterized by perfect competition. In spite of the ubiquitous presence of monopolies and other types of imperfect markets in developed economies whose growth behavior this model is designed to describe, and in spite of the fact that there exists a plethoric number of studies on the static models of imperfect competition, the implications of such market imperfections for stability and dynamic behavior of a growth model have been somehow completely ignored in the 1iterature. The purpose of this paper is to relax the assumption of perfect competition, and explore the consequences of the introduction of "pure" monopoly in the product markets for stability in the traditional two-sector model of economic growth. Some of the results that we derive appear to be very interesting. For example, it turns out that the assumption of a constant propensity to save conflicts with the existence of monopoly equilibrium at any point of time. In other words, the propensity to save must be variable in order to ensure the existence of monopoly equilibrium. Given this necessary condition, the momentary equilibrium under monopoly is always uniquely determined. However, in the long run, the stability of the economic system and attainment of a unique balanced growth path are ensured only under, what is now well known as, the capital-intensity condition. If this condition is not satisfied, the model may actually be unstable.

Section I deals with the assumptions and the model. Section II is concerned with whether or not there exists a wage/rental ratio at which the 
producers'-price ratio is identical with the consumers'-price ratio. It is worth pointing out here that under monopoly, unlike the case in perfect competition, the producers'-price ratio is dependent on the consumers'-price ratio. In Section III the wage/rental ratio is shown to be uniquely related to the overall capital/labor ratio. The question of long run stability of the model is taken up in Section IV. The paper is concluded in Section $V$ with some remarks.

\section{Assumptions and the ModeI}

Except for the presence of monopoly in the product markets, the assumptions of this paper are the same as those of the traditional two-sector growth model. There are two sectors of production, the capital-goods sector (sector 1 ) and the consumption-goods sector (sector 2), with the outputs in these sectors denoted respectively by $\mathrm{y}_{1}$ and $\mathrm{y}_{2}$. There is monopoly in the product markets, but perfect competition in the factor markets; there are two factors of production, capital (K) and labor (L); returns to scale are constant, but returns to factor-proportions are diminishing; full employment, perfect factor mobility, variable propensity to save, a constant rate of depreciation, and an exogenously given rate of growth of labor are also assumed. It is further assumed that there is no freedom of entry in the product markets. 2 The two production functions are:

$$
\begin{aligned}
& \text { (1.1) } y_{1}=L_{1} f_{1}\left(k_{1}\right) \\
& \text { (1.2) } y_{2}=L_{2} f_{2}\left(k_{2}\right),
\end{aligned}
$$

where $L_{i}$ is the labor input and $k_{i}$ is the capital/labor ratio in the $i^{\text {th }}$ sector $(i=1,2)$. The marginal product of capital in the $i^{\text {th }}$ sector $\left(\mathrm{MPK}_{i}\right)$ is given by 


$$
\operatorname{MPK}_{i}=f_{i}^{\prime}
$$

and the marginal product of labor in the $i^{\text {th }}$ sector $\left(M_{1}\right)$ by

$$
\mathrm{MPL}_{i}=f_{i}-k_{i} f_{i}^{\prime}
$$

We assume Inada [5] conditions. That is to say,

$$
\begin{array}{ll}
f_{i}\left(k_{i}\right)>0, & f_{i}^{\prime}\left(k_{i}\right)>0, \\
f_{i}^{\prime \prime}\left(k_{i}\right)<0, & f_{i}^{\prime}(0)=\infty,
\end{array}
$$

and

$$
f_{i}^{\prime}(\infty)=0, \text { for } i=1 \text { and } 2 \text {. }
$$

It may be noted that all marginal factor products depend upon the capital/labor ratio in each sector, given our assumption of linear homogeneity of production functions. And this result holds independent of whether production takes place under conditions of monopoly or perfect competition. However, factor-rewards determination in the two sectors is now different. Under competitive conditions in all markets, the reward of each factor equals its marginal value product and is the same in both sectors. However in the presence of monopoly in the product markets alone, although the factor rewards are still equal in the two industries, the reward of each factor equals its marginal revenue product which, in turn, equals the marginal revenue (MR) times the marginal product. Let $w$ stand for the wage-rate, $r$ for the rental of capital, and $p_{1}$ for the price of the $i^{\text {th }}$ output. Then factor rewards can be written as:

$$
\begin{aligned}
& r=M_{i} M_{i P K_{i}} \\
& w=M_{i} M_{i} .
\end{aligned}
$$

Now as is well known in micro theory, 


$$
\mathrm{MR}_{i}=\mathrm{P}_{i}\left(1-\frac{1}{\varepsilon_{i}}\right)
$$

where $\varepsilon_{i}$ is the price elasticity of demand for the $i^{\text {th }}$ output. Therefore,

(1.3) $r=p_{1}\left(1-\frac{1}{\varepsilon_{1}}\right) f_{1}^{\prime}=p_{2}\left(1-\frac{1}{\varepsilon_{2}}\right) f_{2}^{\prime}$

$(1.4) \quad w=p_{1}\left(1-\frac{1}{\varepsilon_{1}}\right)\left(f_{1}-k_{1} f_{1}^{\prime}\right)=p_{2}\left(1-\frac{1}{\varepsilon_{2}}\right)\left(f_{2}-k_{2} f_{2}^{\prime}\right)$

and

(1.5) $w=\frac{w}{r}=\frac{f_{i}}{f_{i}}-k_{i}$

where $\omega$ is the wage/rental ratio. In perfect competition, the total revenue (TR) earned in an industry is completely exhausted by payments to factors of production, which equal total cost (TC). However, under monopoly TR exceeds TC and the difference equals the excess profit of the monopolist. If we assume that the monopolist is also the owner of capital stock in each industry, then the rate of monopoly profit in the $i^{\text {th }}$ industry $\left(\pi_{i}\right)$ is given by

$$
\pi_{i}=\frac{T R_{i}-T C_{i}}{K_{i}}=\frac{p_{i} y_{i}-\left(r K_{i}+w L_{i}\right)}{K_{i}} .
$$

Straightforward calculations show that ${ }^{3}$

(1.6) $\pi_{i}=\frac{p_{i} f_{i}}{\epsilon_{i} k_{i}}$.

Equations (1.3)-(1.6) deal with the determination of factor rewards. The important point is that there is no conflict between marginal productivity theory and distribution of income when product markets are characterized by monopoly. 
With full employment of factors,

(1.7) $\rho_{1}+\rho_{2}=1$

(1.8) $\rho_{1} k_{1}+\rho_{2} k_{2}=k$

where $k=K / L$ and $\rho_{i}=L_{i} / L$. Let $y$ stand for the national income. Then (1.9) $y=p_{1} y_{1}+p_{2} y_{2}$.

So far we have presented the production side of the model. To complete the model, we also need the demand side which, we assume, is represented by a homogeneous, constant elasticity of substitution (CES) utility function: ${ }^{4}$

$(1.9 *) \quad U=\left[\mathrm{ay}_{1}^{-\beta}+\mathrm{by}_{2}^{-\beta^{-1 / \beta}}\right.$

where $a$ and $b$ are parameters, and where $-1<\beta<\infty, \beta \neq 0$ and $\sigma=\frac{1}{(1+\beta)}, \sigma$ being the elasticity of product substitution between the two outputs. Purely for the sake of simplicity of calculations, we assume that $a / b=1$. From this utility function, the consumption/savings ratio (derived in the next section) is given by

$$
\text { (1.10) } \frac{y_{2}}{y_{1}}=p^{\sigma} \quad\left(p=p_{1} / p_{2}\right)
$$

With this last equation, the presentation of our miniature Walrasian general equilibrium static model under monopoly is complete. ${ }^{5}$ The capital accumulation process in this model is described by

(1.11) $\frac{\dot{\mathrm{k}}}{\mathrm{k}}=\frac{\mathrm{y}_{1}}{\mathrm{k}}-\eta-\mu$

where $\eta$ is the exogenously given rate of growth of labor and $\mu$ is the constant rate of depreciation of capital. 


\section{The Consumer-Producer Equilibrium}

The fundamental difference between perfect competition and monopoly equilibria is that while aggregate demand and supply for products are independent and jointly determine outputs and prices in perfect competition, in monopoly this dichotomy does not exist. The general equilibrium problem under competitive conditions has three aspects. Given a production function and fixed factor and product prices, individual firms attempt to maximize their profits and in the process generate demand for factor services. Their decisions determine demand and supply functions for factor services and outputs, respectively. On the other side, given a utility function and taking the factor and product prices as fixed, the individual households offer factor services and buy goods in such a way as to maximize their flow of satisfaction derived from the consumption of commodities. Their decisions determine supply functions for factor services and demand functions for products. Given these demand and supply functions, equilibrium prices are determined in such a way as to clear all product and factor markets.

However, under monopoly conditions in product markets alone, although the households make their decisions independent of the production side, the individual monopolists need data about demand for their products in order to make profit-maximizing price-output decisions. This is evident from $(1.3)$ and $(1.4)$, because

$$
p=\frac{p_{1}}{P_{2}}=\frac{f_{2}^{\prime}\left(1-\frac{1}{\epsilon_{2}}\right)}{f_{1}^{\prime}\left(1-\frac{1}{\epsilon_{1}}\right)}=\frac{\left(f_{2}-k_{2} f_{2}^{\prime}\right)\left(1-\frac{1}{\epsilon_{2}}\right)}{\left(f_{1}-k_{1} f_{1}^{\prime}\right)\left(1-\frac{1}{\epsilon_{1}}\right)}
$$


In perfect competition

$$
p=\frac{f_{2}^{\prime}}{f_{1}^{\prime}}=\frac{f_{2}-k_{2} f_{2}^{\prime}}{f_{1}-k_{1} f_{1}^{\prime}}
$$

and it is clear that the producers' price ratio is determined independent of the consumers' price ratio furnished by (1.10). However (2.1) shows that under monopoly, producers' price ratio depends not only on marginal factor productivities, but also on the elasticities of demand for the two products. This dependence of monopolist's price on consumers' demand raises an important question about the conditions under which an equilibrium can be shown to exist. In this section, we will show that for any given capital/labor ratio, $k$, all the variables in the model are uniquely related to the wage/rental ratio, $\omega$. It is evident from (2.1) that if $p$ is to be positive, each elasticity of demand must be greater than unity. This is, of course, the well known result in monopoly theory, for the profit maximizing monopolist produces an output where marginal revenue equals positive marginal cost, and the former is positive only if the elasticity of demand exceeds unity. Thus we may conclude that a necessary condition for the monopoly equilibrium to exist is that both price elasticities of demand are greater than unity.

We have already stated that under monopoly producers' price ratio depends among other things, on the two demand elasticities, which in turn can be shown to depend on the price ratio facing the consumers. Suppose we impose any price ratio on the consumers. From (1.10) we know that the ratio in which commodities may be consumed is uniquely determined by the product-price ratio. Corresponding to this price ratio, there also exists a set of elasticities of demand and given these and the marginal factor 
productivities from the production functions, the producers' price ratio will be determined uniquely from (2.1). The question is whether or not, and under what conditions, the producers' price ratio will be the same as the price ratio that was initially imposed on the consumers. The utility function from $(1.9 *)$ is

(1.9*) $\quad U=\left[a y_{1}^{-\beta}+b y^{-\beta}\right]^{-1 / \beta}$

where $-1<\beta<\infty, \beta \neq 0$ and $\sigma=\frac{1}{(1+\beta)}$. For this utility function, the demand functions, remembering that $a / b=1$, are: ${ }^{6}$

$$
y_{1}=\frac{y}{p_{1}\left(1+p^{-\beta \sigma}\right)}
$$

and

$$
\text { (2.3) } \quad y_{2}=\frac{y}{p_{2}\left(1+p^{\beta \sigma}\right)} \text {. }
$$

The corresponding demand elasticities are

$$
\text { (2.4) } \quad \epsilon_{1}=\frac{1+\sigma \mathrm{p}^{-\beta \sigma}}{1+\mathrm{p}^{-\beta \sigma}}
$$

and

$$
\text { (2.5) } \quad \epsilon_{2}=\frac{1+\sigma p^{\beta \sigma}}{1+p^{\beta \sigma}}
$$

where $\quad \epsilon_{i}=-\frac{\partial y_{i}}{\partial p_{i}} \frac{p_{i}}{y_{i}}$ $(i=1,2)$

Dividing $y_{2}$ by $y_{1}$, we can also obtain: 
(1.10)

$$
\frac{y_{2}}{y_{1}}=x=\frac{p\left(1+p^{\beta \sigma}\right) / p^{\beta \sigma}}{1+p^{\beta \sigma}}=p^{1-\beta \sigma}=p^{\sigma}
$$

An examination of $(2.4)$ and (2.5) reveals that both $\epsilon_{1}$ and $\epsilon_{2}$ exceed unity if and only if $\sigma>1$. Thus we conclude that the existence of monopoly equilibrium requires that $\sigma$, the elasticity of product substitution, exceed unity which, in turn, means that $\beta<0 .{ }^{7}$ It is also clear that both elasticities of demand depend only on the price ratio facing the consumers.

We are now in a position to show that $\sigma>1$ implies a variable propensity to save. From (1.9) and (1.10) we have:

$$
s=\frac{p_{1} y_{1}}{y}=\frac{1}{1+p^{\sigma-1}}
$$

where $s$ is the average propensity to save, so that

$$
\mathrm{ds}=\frac{\left[(1-\sigma) \mathrm{p}^{\sigma-2}\right] \mathrm{dp}}{\left(1+\mathrm{p}^{\sigma-1}\right)^{2}} \text {. }
$$

Evidently $\mathrm{ds}=0$ only if $\sigma=1$, and if $\sigma>1, \mathrm{ds} / \mathrm{dp}<0$. In other words, the necessary condition for monopoly equilibrium to exist is that the propensity to save be variable. A constant propensity to save and monopoly do not coexist.

In order to facilitate further exposition, we will now establish a number of lemmas.

Lemma 1: a) $\epsilon_{1}$ is a monotonic increasing function and $\varepsilon_{2}$ is a monotonic decreasing function of $x$. Furthermore,

$$
\text { b) } \begin{array}{ll}
\lim \epsilon_{1}=\sigma ; & \lim \epsilon_{1}=1 \\
x \rightarrow \infty & x \rightarrow 0
\end{array}
$$


and

$$
\begin{array}{ll}
\lim _{x \rightarrow \infty} \epsilon_{2}=1 ; & \lim \epsilon_{2}=\sigma \\
x \rightarrow 0 . &
\end{array}
$$

Proof: Substituting $x=p^{\sigma}$ from $(1.10)$ in $(2.4)$ and $(2.5)$, we obtain:

$$
\text { (2.7) } \quad \varepsilon_{1}=\frac{1+\sigma x^{-\beta}}{1+x^{-\beta}}
$$

and

$$
\text { (2.8) } \quad \epsilon_{2}=\frac{1+\sigma x^{\beta}}{1+x^{\beta}} \text {. }
$$

These equations show that $\epsilon_{1}$ and $\epsilon_{2}$ depend only on $x$, because

$$
\text { (2.9) } \frac{\mathrm{d} \epsilon_{1}}{\mathrm{dx}}=\frac{\beta(1-\sigma) \mathrm{x}^{-(1+\beta)}}{\left(1+\mathrm{x}^{-\beta}\right)^{2}}>0
$$

and

(2.10) $\frac{\mathrm{d} \varepsilon_{2}}{\mathrm{dx}}=\frac{\beta(\sigma-1) \mathrm{x}^{\beta-1}}{\left(1+\mathrm{x}^{\beta}\right)^{2}}<0$.

Given our assumption that $\sigma>1$ and $\beta<0, d \epsilon_{1} / d x>0$ and $d \epsilon_{2} / d x<0$. This establishes Lemma $1(a)$.

Equation (2.7) can be written as:

$$
\text { (2.7*) } \quad \epsilon_{1}=\frac{\sigma+\frac{1}{x^{-\beta}}}{1+\frac{1}{x^{-\beta}}} \text {. }
$$

Since $\beta<0,1 / x^{-\beta}$ tends to zero as $x$ tends to infinity. Therefore

$$
\lim _{x \rightarrow \infty} \varepsilon_{1}=\sigma
$$

similarly, from (2.7) it is evident that 


$$
\begin{aligned}
& \lim \epsilon_{1}=1 \\
& x \rightarrow 0 .
\end{aligned}
$$

With this, the first half of Lemma $1(b)$ is established. The remaining expressions In Lemma 1(b) can be derived in the same way. For the sake of further comprehension of Lemma 1, consider the transformation curve TT' in Figure 1 which is drawn for any given $k$. As we move close to point $T$, the output ratio $x$ rises and and so does $\epsilon_{1}$, whereas $\varepsilon_{2}$ declines towards unity. In the 1 imit, at point $T$, where no $y_{1}$ is produced, $x=\infty, \varepsilon_{1}=\sigma$ and $\varepsilon_{2}=1$. The opposite is true at point $T^{\prime}$, where no $y_{2}$ is produced, $x=0, \epsilon_{1}=1$, and $\epsilon_{2}=\sigma$. Thus, if monopoly is to exist in both sectors, points $T$ and $T^{\prime}$ cannot be the equilibrium production points since, for both demand elasticities to exceed unity, the production point must be somewhere between $T$ and $T^{\prime}$.

Lemma 2: a) At any given $k$, the output ratio, $x$, is a monotonic decreasing or a monotonic increasing function of $w$ depending on whether $k_{2}>k_{1}$ or $k_{2}<k_{1}$. Furthermore, b) if $k_{2}>k_{1}$,

$$
1 \text { im } x=0 ; \quad 1 \text { im } x=\infty,
$$
$\omega \rightarrow \infty$
$\omega \rightarrow 0$

and c) if $k_{2}<k_{1}$,

$$
\begin{array}{ll}
\lim x=\infty ; & 1 . \lim x=0 \\
\omega \rightarrow \infty & \omega \rightarrow 0
\end{array}
$$

Proof: From (1.7) and (1.8),

$$
\text { (2.11) } \quad \rho_{1}=\frac{k_{2}-k}{k_{2}-k_{1}}
$$

and

$$
\rho_{2}=\frac{k-k_{1}}{k_{2}-k_{1}} \text {, }
$$


$-12-$

$\stackrel{8}{3}$

$=$

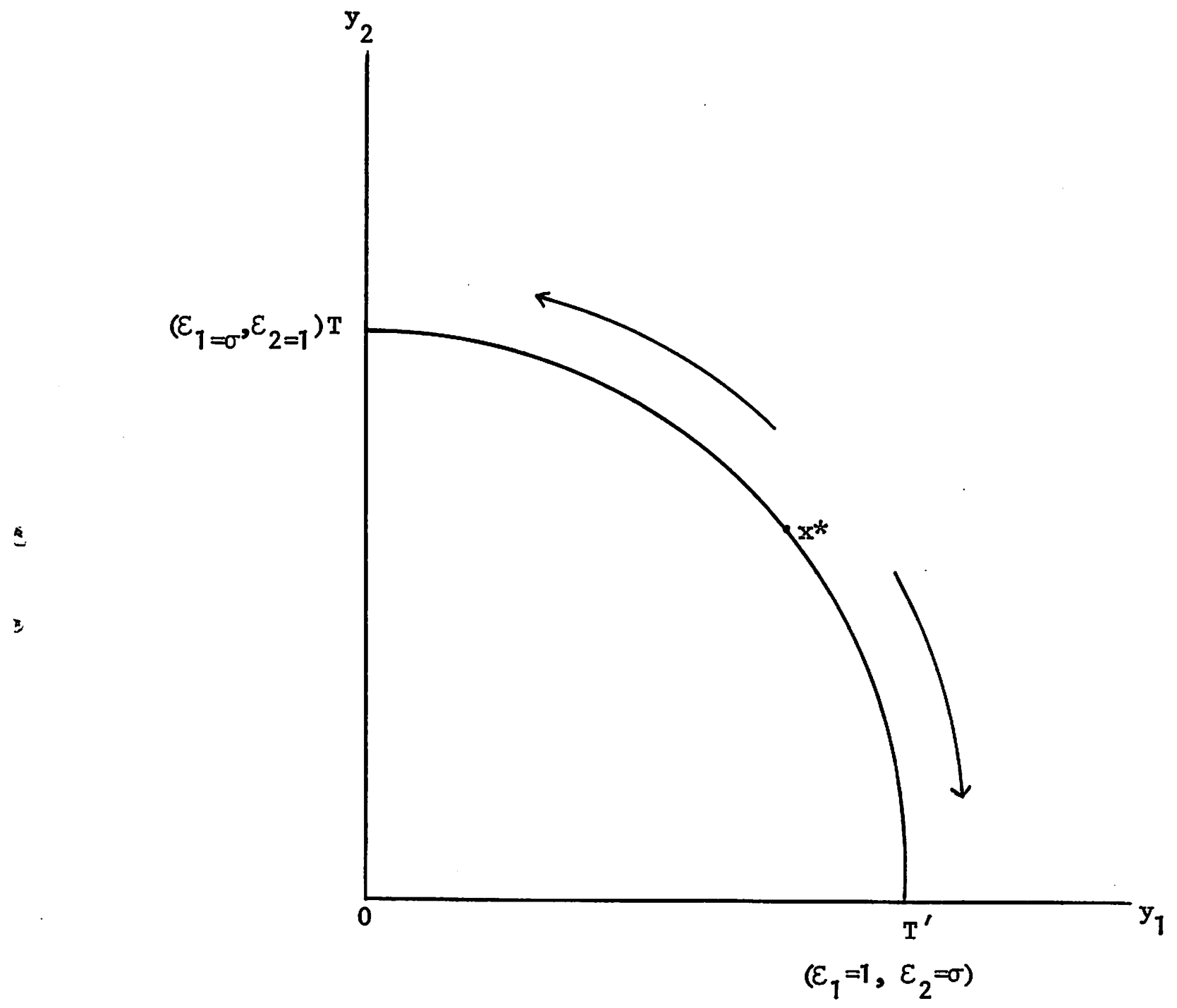

Figure 1 
and from $(1.1),(1.2),(2.11)$ and $(2.12)$

(2.13) $\quad x=\frac{y_{2}}{y_{1}}=\frac{\rho_{2} f_{2}}{\rho_{1} f_{1}}=\frac{f_{2}\left(k-k_{1}\right)}{f_{1}\left(k_{2}-k\right)}$.

Differentiating (1.5) with respect to $\omega$, we have

(2.14) $\quad \frac{d k_{i}}{d \omega}=-\frac{f_{i}^{\prime 2}}{f_{i}^{\prime \prime} f_{i}^{\prime \prime}}$.

In view of $\mathrm{f}_{i}^{\prime \prime}<0, \mathrm{dk}_{\mathrm{i}} / \mathrm{d} \omega>0$. Under Inada conditions stated earlier,

(2.15) $\quad \lim k_{i}(\omega)=\infty$

$\omega \rightarrow \infty$

and

(2.16) $\quad \lim k_{i}(\omega)=0$

$\omega \rightarrow 0$.

Differentiating $(2.13)$ with respect to $w$ and remembering that $k$ is kept constant, we have:

(2.17) $\frac{\partial x}{\partial w}=-\frac{f_{2}\left(k_{2}-k\right)\left[\left(f_{1}-k_{1} f_{1}^{\prime}\right)+k f_{1}^{\prime}\right] k_{1}^{\prime}+f_{1}\left(k-k_{1}\right)\left[\left(f_{2}-k_{2} f_{2}^{\prime}\right)+k f_{2}^{\prime}\right] k_{2}^{\prime}}{\left[\left(k_{2}-k\right) f_{1}\right]^{2}}$

where $\mathrm{k}_{1}^{\prime} \equiv \mathrm{dk_{1 }} / \mathrm{d} \omega>0$.

Now in a two-sector model where both sectors have positive outputs,

$$
\mathrm{k}_{2} \gtrless \mathrm{k} \gtrless \mathrm{k}_{1} \text {. }
$$

Under the capital-intensity condition where $k_{2}>k>k_{1}, \partial x / \partial<0$, whereas if $k_{2}<k<k_{1}, \partial x / \partial \omega>0$. This establishes Lemma $2(a)$.

Lemmas $2(b)$ and $2(c)$ can be proved simply by referring to Figure 1.

Since the wage/rental ratio is the same in the two sectors, any production point 
w111 lie on the EdgeworthBowley contract curve plotted in a box diagram or, what is the same thing, on the transformation curve TT'. Suppose $x^{*}$ is one such point corresponding to some $\omega$. If $k_{2}>k_{1}$, a rise in $\omega$ will result in a movement of the production point in the direction of the arrow towards $T^{\prime}$. As $\omega$ continues to rise, $x$ will continue to decline and in the limit will fall to zero at $T^{\prime}$. In other words, if $k_{2}>k_{1}$,

$$
\lim x=0
$$$$
\omega \rightarrow \infty \text {. }
$$

Similarly, a decline in $w$, under the capital-intensity condition, will result In the movement of $x^{*}$ towards $T$, and in the 1 imit $x$ will equal infinity, so that

$$
\lim x=\infty
$$

$$
\omega \rightarrow 0
$$

This proves Lemma 2(b). Lemma 2(c) can be proved analogously.

Lemma 3: a) Under the capital-intensity condition, $\varepsilon_{1}$ is a monotonic decreasing and $\varepsilon_{2}$ a monotonic increasing function of $\omega$ for any $k$. Furthermore,

$$
\text { b) } \begin{array}{ll}
\lim \epsilon_{1}(\omega)=1 ; & \lim \epsilon_{1}(\omega)=\sigma \\
\omega \rightarrow \infty & \omega \rightarrow 0
\end{array}
$$

and

$$
\begin{array}{ll} 
& \lim \epsilon_{2}(\omega)=\sigma ; \\
\omega \rightarrow \infty & \epsilon_{2}(\omega)=1 \\
\omega \rightarrow 0 &
\end{array}
$$

Lema 4: a) If the capital-intensity condition is not satisfied, then for any $k, \epsilon_{1}$ is a monotonic increasing and $\epsilon_{2}$ a monotonic decreasing function of w. This is just the opposite of Lemma 3(a). Furthermore, Lemmas $3(\mathrm{~b})$ and 3(c) are also reversed. 
Proof: Combining equations (2.9) and (2.10) with (2.17), we have:

(2.18) $\frac{\partial \epsilon_{1}}{\partial \omega} \lesseqgtr 0$, if $k_{2} \gtrless k_{1}$

and

$$
\frac{\partial \varepsilon_{2}}{\partial w} \gtrless 0 \text {, if } k_{2} \gtrless k_{1} \text {. }
$$

This proves Lemmas $3(a)$ and $4(a)$. Similarly, Lemmas $3(b), 3(c)$ and $4(b)$ and $4(c)$ can be established from Lemmas $1(b), 2(b)$ and $2(c)$.

Lemmas (3) and (4) are geometrically depicted in Figures 2 (a) and $2(\mathrm{~b})$, where demand elasticities are represented along the vertical axis and the wage/rental ratio along the horizontal axis. In both diagrams, the $\epsilon_{1}$ and $\epsilon_{2}$ curves are bounded by unity and $\sigma$. In Figure $2(a)$, which is drawn under the capital-intensity hypothesis, $\epsilon_{1}$ is shown to be a decreasing and $\epsilon_{2}$ an increasing function of $w$. The opposite holds in Figure $2(b)$. There is one wage/rental ratio where the two demand elasticities are equal, and this is given by $\omega^{\prime}$. However, $\omega^{\prime}$ is one among an infinity of wage/rental ratios consistent with equilibrium, and should not be confused with an equilibrium w. With a number of lemmas already established, we are now in a position to relate the consumers'-price ratio, $p_{c}$, (obtainable from $(1.10)$ ) and the producers'-price ratio, $\mathrm{p}_{\mathrm{p}}$, (obtainable from $(2.1)$ ) to the wage/rental ratio. The following lemmas may now be derived.

Lemma 5: a) The consumers'-price ratio, $\mathrm{p}_{\mathrm{c}}$, is a monotonic decreasing function or a monotonic increasing function of $w$ for any given $k$, depending on whether or not the capital-intensity condition is satisfied. Furthermore, b) if $k_{2}>k_{1}$

$$
\begin{array}{ll}
\lim p_{c}=0 ; & \lim p_{c}=\infty \\
\omega \rightarrow \infty & \omega \rightarrow 0
\end{array}
$$




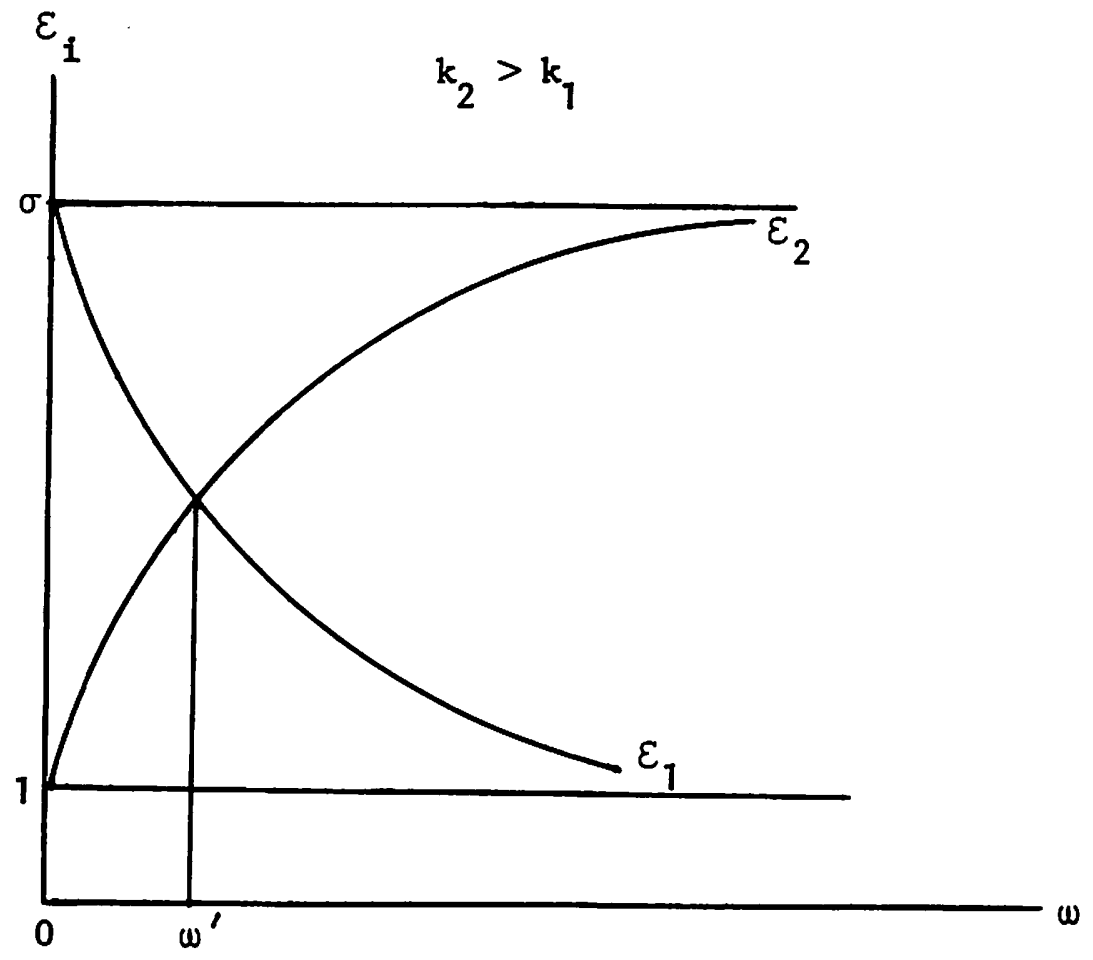

Figure 2(a)

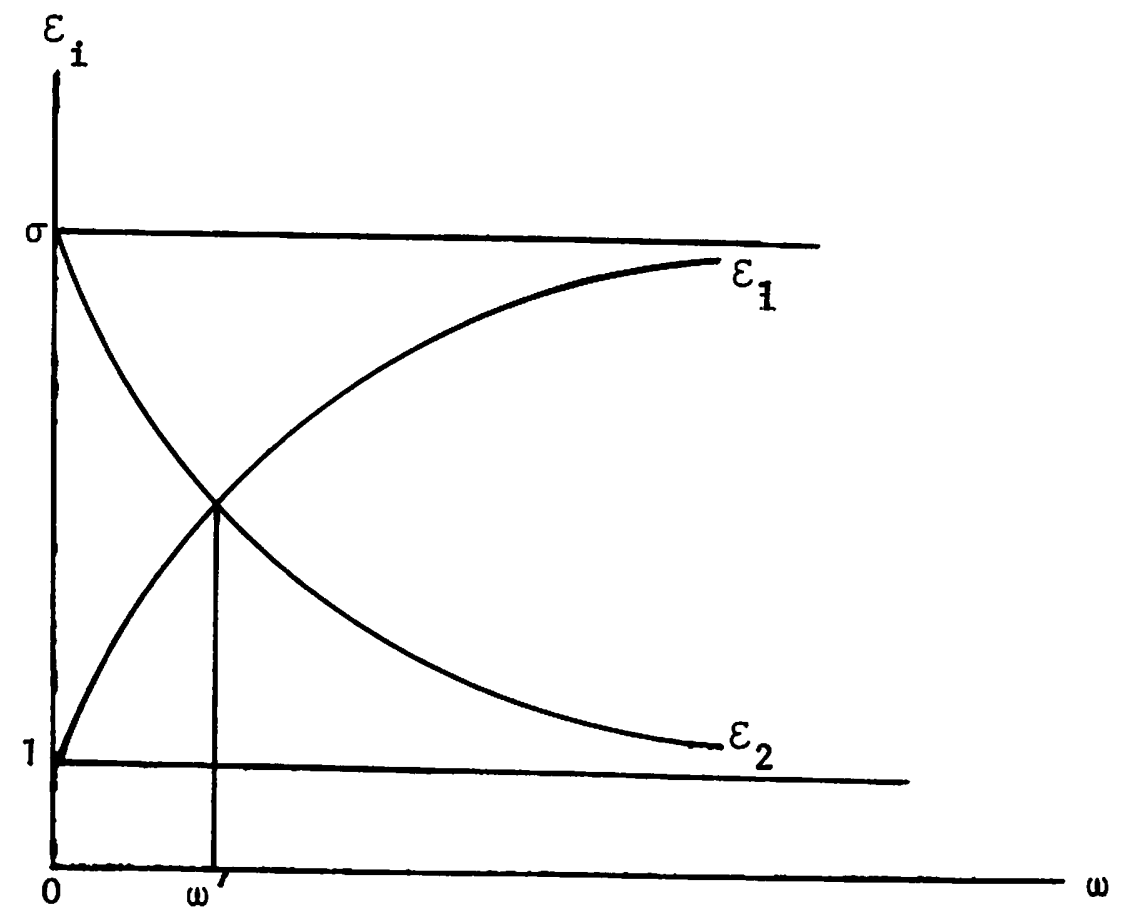

Figure 2(b) 
and c) if $k_{2}<k_{1}$

$$
\begin{array}{ll}
\lim _{\omega \rightarrow \infty} \mathrm{p}_{c}=\infty ; & \lim \mathrm{p}_{c}=0 \\
\omega \rightarrow 0 .
\end{array}
$$

Proof: Differentiating (1.10) with respect to $\omega$ we have:

(2.20) $\quad \frac{\partial \mathrm{p}_{\mathrm{c}}}{\partial w}=\frac{1}{\sigma \mathrm{p}_{\mathrm{c}}} \frac{\partial \mathrm{x}}{\partial w}$.

Since from (2.17) $\partial x / \partial \omega>0$ if $k_{2} \gtrless k_{1}$, it is clear from (2.20) that

$\partial \mathrm{p}_{\mathrm{c}} / \partial \omega \lessgtr 0$ if $\mathrm{k}_{2} \gtrless \mathrm{k}_{1}$. This proves Lemma $5(\mathrm{a})$. Lemmas $5(\mathrm{~b})$ and $5(\mathrm{c})$ may now be established in two steps. Differentiating (1.10) with respect to $x$ we have:

(2.21) $\quad \frac{\mathrm{dp}_{\mathrm{c}}}{\mathrm{dx}}=\frac{1}{\sigma \mathrm{p}_{c}^{\sigma-1}}>0$.

In other words $\mathrm{p}_{c}$ is a monotonic increasing function of $x$. Furthermore, under CES functions with elasticity of substitution greater than unity, it can be easily shown that

(2.22) $\quad \lim \mathrm{p}_{\mathrm{c}}=\infty$, and $\lim \mathrm{p}_{\mathrm{c}}=0$

$$
\mathbf{x} \rightarrow \infty \quad \mathrm{x} \rightarrow 0 \text {. }
$$

This is because for CES functions where $-1<\beta<0$, the indifference curves touch the axes at points of tangency, as shown in Figure $3^{8}$ Then from lemma (2), Lemmas $5(\mathrm{~b})$ and $5(\mathrm{c})$ can be easily proved.

Lemma 6: a) At any $k$, the producers' price ratio, $\mathrm{p}_{\mathrm{p}}$, is a monotonic increasing or a monotonic decreasing function of $w$, depending on whether or not the capitalintensity condition is satisfied. Furthermore, b) if $k_{2}>k_{1}$,

$$
\lim \mathrm{p}_{\mathrm{p}}=\infty ; \quad \lim \mathrm{p}_{\mathrm{p}}=0
$$

$\omega \rightarrow \infty \quad \omega \rightarrow 0$ 


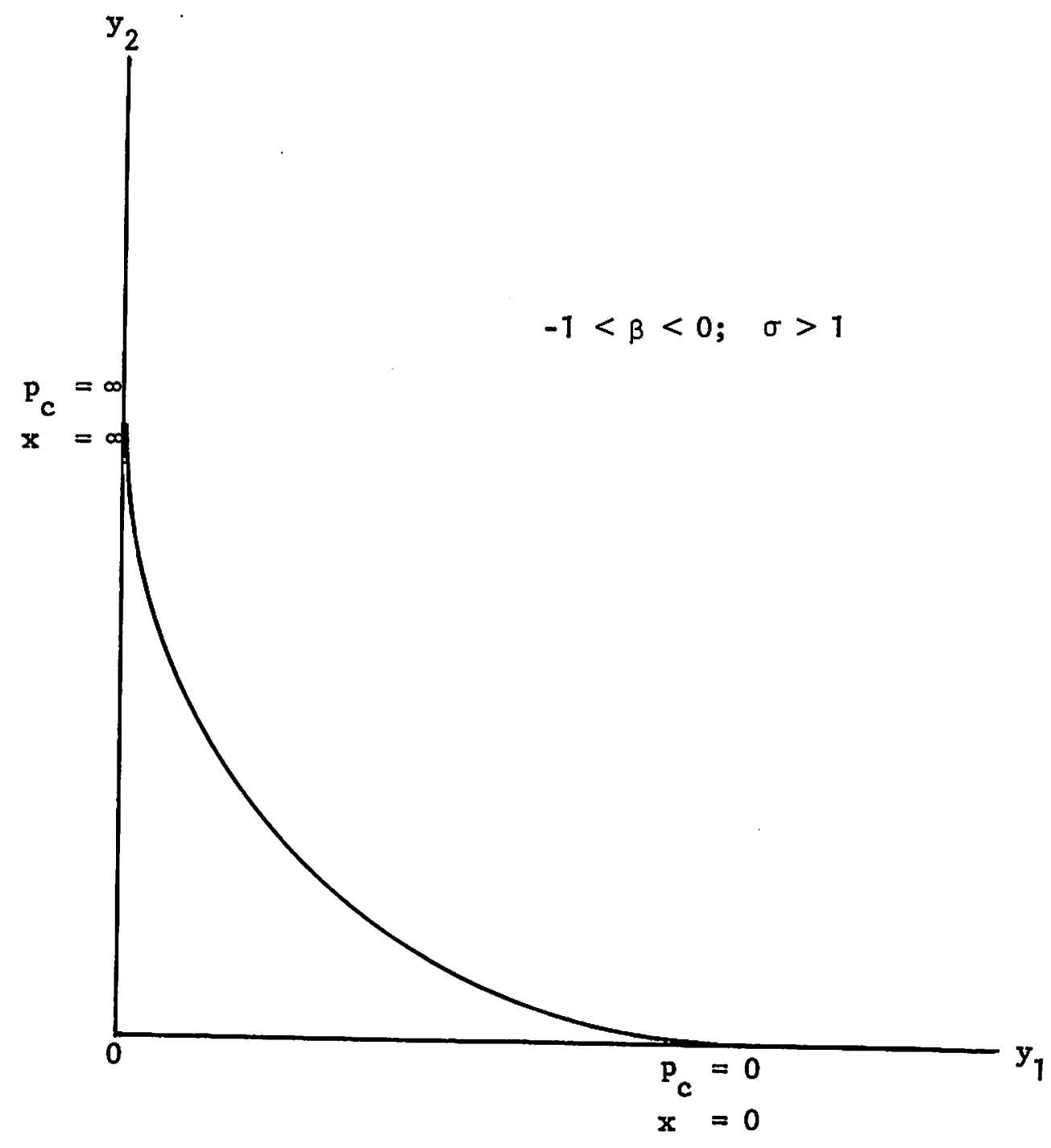

Figure 3 
and c) if $k_{2}<k_{1}$

$$
\begin{array}{ll}
\lim p_{p}=0 ; & \lim p_{p}=\infty \\
\omega \rightarrow \infty & \omega \rightarrow 0 .
\end{array}
$$

Proof: Differentiating (2.1) with respect to $\omega$ we have:

$$
\text { (2.23) } \frac{\partial \mathrm{p}_{\mathrm{p}}}{\partial \omega}=\frac{\mathrm{f}_{2}^{\prime}}{\mathrm{f}_{1}^{\prime}\left(1-\frac{1}{\epsilon_{1}}\right)}\left[\frac{\left(1-\frac{1}{\epsilon_{1}}\right)\left(1-\frac{1}{\epsilon_{2}}\right)\left(\mathrm{k}_{2}-\mathrm{k}_{1}\right)}{\left(\omega+\mathrm{k}_{1}\right)\left(\omega+\mathrm{k}_{2}\right)}+\left\{\frac{\left(1-\frac{1}{\epsilon_{1}}\right) \mathrm{d} \epsilon_{2}}{\epsilon_{2}^{2} \mathrm{dx}}-\frac{\left(1-\frac{1}{\epsilon_{2}}\right) \mathrm{d} \epsilon_{1}}{\epsilon_{1}^{2}} \frac{\partial \mathrm{x}}{\mathrm{dx}}\right\} \frac{\partial \omega}{\partial \omega}\right] \text {. }
$$

In the derivation of $(2.23)$ use has been made of the following relations obtainable from (1.5):

$$
\text { i) } \frac{f_{1}^{\prime}}{f_{1}}=\frac{1}{\omega+k_{1}}
$$

and

$$
\text { ii) } \frac{f_{2}^{\prime}}{f_{2}}=\frac{1}{w+k_{2}} \text {. }
$$

Under the capital-intensity condition, the first term within the brackets is positive; the second term is also positive, because from (2.17) $\partial x / \partial \omega<0$ and from (2.9) and (2.10), $\mathrm{d} \varepsilon_{1} / \mathrm{dx}>0$ and $\mathrm{d} \epsilon_{2} / \mathrm{dx}<0$. Hence when $\mathrm{k}_{2}>\mathrm{k}_{1}$

$$
\frac{\partial p}{\partial \omega}>0
$$

Similarly, when $k_{2}<k_{1}$

$$
\frac{\partial p_{p}}{\partial \omega}<0 \text {. }
$$

With this Lemma $6(a)$ is established. Lemmas $6(b)$ and $6(c)$ may be established as follows. We have already shown that

$$
p_{p}=\frac{f_{2}^{\prime}\left(1-1 / \epsilon_{2}\right)}{f_{1}^{\prime}\left(1-1 / \epsilon_{1}\right)} \text {. }
$$

Now $f_{2}^{\prime} / f_{1}^{\prime}$ is an increasing function of $\omega$ if $k_{2}>k_{1}$, and a decreasing function of $\omega$ if $k_{2}<k_{1}$. This is clear from the first term within the brackets of (2.23). From Lemma (3), it can be proved that for $k_{2}>k_{1}$, 


$$
\lim _{\omega \rightarrow \infty} \frac{\left(1-1 / \epsilon_{2}\right)}{\left(1-1 / \varepsilon_{1}\right)}=\infty
$$

and

$$
\text { (2.25) } \quad \lim _{\omega \rightarrow 0} \frac{\left(1-1 / \epsilon_{2}\right)}{\left(1-1 / \epsilon_{1}\right)}=0
$$

Furthermore, it is also clear that both $f_{2}^{\prime} / f_{1}^{\prime}$ and $\left(1-1 / \epsilon_{2}\right) /\left(1-1 / \epsilon_{1}\right)$ are increasing functions of $\omega$ when $k_{2}>k_{1}$. Then since the 1 imit of a product equals the product of the limits, Lemma $6(\mathrm{~b})$ is established. Lemma $6(\mathrm{c})$ can be similarly proved from Lemma 4 under the assumption that $k_{2}<k_{1}$.

From Lemma 5 and Lemma 6, the following theorem is immediate.

Theorem 1: For a CES utility function, and assuming that $-1<\beta<0$ or that $\sigma>1$, there exists a unique $\omega$ at which the producers'-price ratio and the consumers'-price ratio, satisfying, respectively, (2.1) and (1.10), are equal.

The theorem can be best illustrated by referring to Figure 4, where $\mathrm{p}_{c}$ and $\mathrm{P}_{\mathrm{p}}$ are depicted as functions of $w$ in accordance with Lemmas 5 and 6 . In Figure $4(a)$, $k_{2}>k_{1}$, and $p_{p}$ is shown to be an increasing function and $p_{c}$ a decreasing function of $w_{\text {. Figure }} 4(\mathrm{~b})$ is drawn on the reverse assumption of $k_{2}<k_{1}$. The equilibrium price ratio is $\mathrm{p}^{*}$ and corresponding to it, the equilibrium wage/rental ratio is $\omega^{*}$.

So far we have assumed a CES utility function with $-1<\beta<0$ and shown that monopoly equilibrium exists for any $k$. However, this type of utility function is only a sufficient condition for the uniqueness of monopoly equilibrium at any $k$; it is not a necessary condition. It is clear from Figure 4 that in general $p_{p}$ and $p_{c}$ need not range from 0 to $\infty$. For example, consider Figure $4(a)$. If $p_{p}$ starts from the origin, then any homogeneous concave utility function, which ensures that $p_{c}$ is a decreasing function of $w$, will furnish a unique equilibrium. Thus for a unique equilibrium to exist, it is by no means necessary that the utility function be of the CES type. In general, the monopoly equilibrium will be unique, if 
$-21-$

Figure $4(a)$

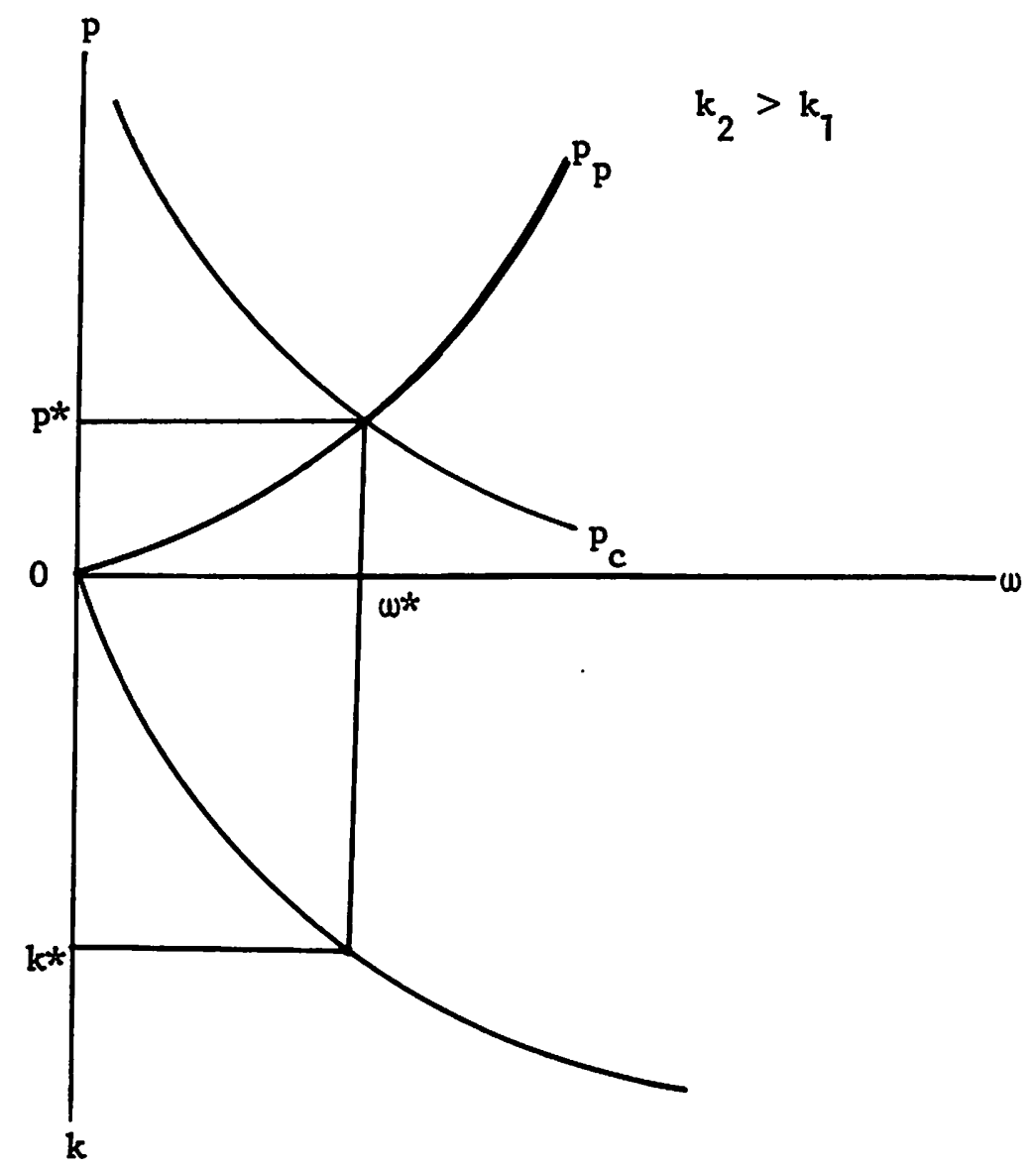

Figure $4(\mathrm{~b})$

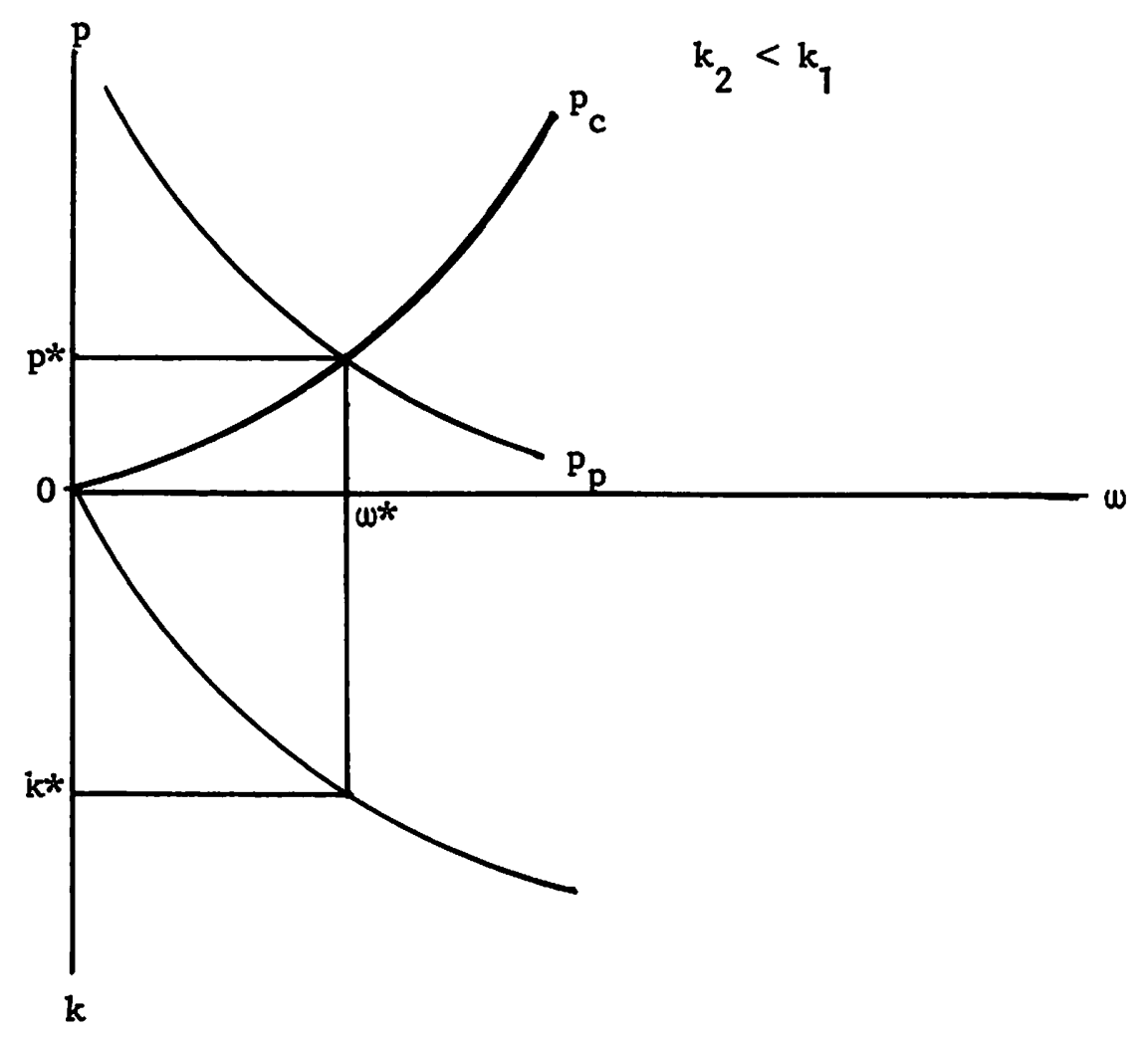


i) there exists a range of $w$ for which both demand elasticities exceed unity, and

ii) the relationship between $\epsilon_{i}$ and $\omega$ is in accordance with that described by Lemmas 3 and 4 .

III. Uniqueness of the Momentary Equilibrium

In the previous section we have shown that all the variables can be uniquely determined from $w$. In this section we will show that $w$ can be uniquely determined from $k$, so that at any moment of time, when $k$ is taken to be given, the monopoly equilibrium will be uniquely determined. In other words, we will show that the momentary equilibrium is uniquely determined under all conditions, provided the necessary condition for the existence of monopoly equilibrium established in the previous section, namely $\sigma>1$, is satisfied. Substituting $x$ from $(2.13)$ in $(1.10)$ we have:

(3.1) $\quad x=\frac{f_{2}\left(k-k_{1}\right)}{f_{1}\left(k_{2}-k\right)}=p^{\sigma}$

In equilibrium, the consumers'-price ratio is the same as the producers'-price ratio. In other words, p can be substituted from $(2.1)$, so that $(3.1)$ can be written as:

$$
\frac{f_{2}\left(k-k_{1}\right)}{f_{1}\left(k_{2}-k\right)}=\left[\frac{f_{2}^{\prime}\left(1-\frac{1}{\epsilon_{2}}\right)}{f_{1}^{\prime}\left(1-\frac{1}{\varepsilon_{1}}\right.}\right] .
$$

Solving for $k$, then gives us:

$$
\begin{aligned}
& \text { (3.3) } \quad k=\frac{A_{1} \lambda_{1} k_{1}+A_{2} \lambda_{2} k_{2}}{A_{1} \lambda_{1}+A_{2} \lambda_{2}}=\psi(w) \\
& \text { where } A_{1}=f_{2} f_{1}^{\prime \sigma}, A_{2}=f_{1} f_{2}^{\prime} \text { and } \lambda_{i}=\left(1-1 / \varepsilon_{i}\right)^{\sigma} \text {. Differentiating (3.3) totally }
\end{aligned}
$$


with respect to $\omega$, we obtain:

(3.4) $\frac{\mathrm{dk}}{\mathrm{d} \omega}=\frac{1}{\mathrm{D}_{1}^{2}}\left[\left(\mathrm{~A}_{1}^{2} \lambda_{1}^{2} \mathrm{k}_{1}^{\prime}+\mathrm{A}_{2}^{2} \lambda_{2}^{2} \mathrm{k}_{2}^{\prime}\right)+\lambda_{1} \lambda_{2} \mathrm{~A}+\mathrm{A}_{1} \mathrm{~A}_{2}\left(\lambda_{1} \lambda_{2}^{\prime}-\lambda_{2} \lambda_{1}^{\prime}\right)\left(\mathrm{k}_{2}-\mathrm{k}_{1}\right)\right]^{9}$

where $A=A_{1} k_{2} A_{2}^{\prime}+A_{1} A_{2} k_{2}^{\prime}+A_{2} k_{1} A_{1}^{\prime}+A_{1} A_{2} k_{1}^{\prime}-A_{1} k_{1} A_{2}^{\prime}-A_{2} k_{2} A_{1}^{\prime}$,

$k_{i}^{\prime}=d k_{i} / d \omega>0(i=1,2), D_{1}^{2}=\left(A_{1} \lambda_{1}+A_{2} \lambda_{2}\right)^{2}$, and $\lambda_{i}^{\prime}=d \lambda_{i} / d \omega$. Differentiating $\lambda_{i}$ with respect to $\omega$ and utilizing $(2-7)-(2.10)$ we obtain:

$(3.5)^{10} \quad \lambda_{1} \lambda_{2}^{\prime}-\lambda_{2} \lambda_{1}^{\prime}=\sigma \beta \lambda_{1} \lambda_{2}\left[\frac{x^{-(1+\beta)}}{\left(1+\sigma x^{-\beta}\right)}+\frac{x^{-1}}{\left(1+\sigma x^{\beta}\right)}\right] \frac{d x}{d \omega}=-G \frac{d x}{d \omega}$ where $G>0$. Differentiating (2.13) totally with respect to $\omega$, we have:

(3.6) $\frac{d x}{d \omega}=\frac{1}{D_{2}^{2}}\left[f_{1} f_{2}\left(k_{2}-k_{1}\right) \frac{d k}{d \omega}-k_{1}^{\prime} f_{2}\left(k_{2}-k\right) F_{1}-k_{2}^{\prime} f_{1}\left(k-k_{1}\right) F_{2}\right]$

where $D_{2}^{2}=\left[\left(k_{2}-k\right) f_{1}\right]^{2}$, and $F_{i}=\left(f_{i}-k_{i} f_{i}^{\prime}\right)+k f_{i}^{\prime}>0, \quad i=1,2$.

Substituting (3.5) and (3.6) in (3.4) we derive:

(3.7) $\frac{d k}{d \omega}=\frac{Q_{1} k_{1}^{\prime}+Q_{2} k_{2}^{\prime}+Q}{D}$

where $Q_{1}=D_{2}^{2} A_{1}^{2} \lambda_{1}^{2}+D_{1}^{2} A_{1} A_{2} G f_{2}\left(k_{2}-k_{1}\right)\left(k_{2}-k\right) F_{1}>0$,

$$
\begin{aligned}
& Q_{2}=D_{2}^{2} A_{2}^{2} \lambda_{2}^{2}+D_{1}^{2} A_{1} A_{2} G f_{1}\left(k_{2}-k_{1}\right)\left(k-k_{1}\right) F_{2}>0, \\
& Q=D_{2}^{2} A \lambda_{1} \lambda_{2}>0^{11}, \text { and } \\
& D=D_{1}^{2} D_{2}^{2}+D_{1}^{2} A_{1} A_{2} G\left(k_{2}-k_{1}\right)^{2} f_{1} f_{2}>0 .
\end{aligned}
$$

Since $Q_{1}, Q_{2}, Q$ and $D$ are all positive, $d k / d \omega>0$. In other words, $\omega$ is uniquely determined from $k$. Here it is worth pointing out that all the elements of $d k / d \omega$ 
in (3.7) are shown to be unambiguously positive only because $G$ is positive, which, in turn, means from (3.5) that $\beta<0$ and $\sigma>1$. The following theorem is then immediate.

Theorem 2: A sufficient condition for $\omega$ to be uniquely determined by $k$, or, what is the same thing, for the uniqueness of momentary equilibrium under monopoly when community preferences are represented by a CES utility function, is that the elasticity of substitution between the two outputs is greater than unity.

Once $w$ is uniquely determined from $k$, then as we have established in the previous section, all the economic variables are uniquely determined in equilibrium, given, of course, that $\sigma>1$, or equivalently, the propensity to save is variable. This unique determination of monopoly equilibrium is depicted in Figures $4(a)$ and 4(b). In the lower positions of the diagrams, we plot the positive relation between $k$ and $\omega_{\text {. }}$ Suppose at any moment of time, $k$ is given by $k *$; then in equilibrium $\omega$ equals $\omega^{*}$ and $p$ equals $p *$. With the determination of $\omega$, the rest of the variables are easily determined. It is of interest to note that under perfect competition in both sectors, the momentary equilibrium is uniquely determined irrespective of the value of $\sigma$. Because, here, $\lambda_{i}^{\prime}=0$, and $\lambda_{1}=\lambda_{2}=1$, so that $\mathrm{dk} / \mathrm{d} \omega>0$ for all values of $\sigma$.

\section{Existence and Stability of the Long Run Equilibrium}

The capital accumulation process described by (1.11) may be written as:

$$
\text { (4.1) } \quad \frac{\dot{\mathrm{k}}}{\mathrm{k}}=\frac{\mathrm{y}_{1}}{\mathrm{k}}-(\eta+\mu) \text {. }
$$

where $\eta$ is the exogenously given rate of growth of labor and $\mu$ is the constant rate of depreciation. Using $(1.1),(4.1)$ can be written as:

$$
\text { (4.2) } \quad \frac{k}{k}=\frac{\rho_{1} f_{1}}{k}-(\eta+\mu) \text {. }
$$

Substituting (2.11) in (4.2), we have: 
(4.3) $\quad \frac{\dot{k}}{k}=\frac{f_{1}\left(k_{2}-k\right)}{k\left(k_{2}-k_{1}\right)}-(\eta+\mu)$.

It is assumed that the differential equation (4.3) with any positive initial condition has a solution continuous with respect to the initial condition. Let k* be the capital/1abor ratio such that

(4.4) $\frac{\mathrm{f}_{1}^{*}\left(\mathrm{k}_{2}^{*}-\mathrm{k}^{*}\right)}{\mathrm{k}^{*}\left(\mathrm{k}_{2}^{*}-\mathrm{k}_{1}^{*}\right)}=\eta+\mu$,

where $\mathrm{f}_{1}^{*}, \mathrm{k}_{2}^{*}$ and $\mathrm{k}_{1}^{*}$ all correspond to $\mathrm{k}^{*}$, which we call the balanced capital/1abor ratio. We will now show that under the capital-intensity condition, the balanced capital ratio, $k^{*}$, is uniquely determined, and the balanced growth path corresponding to $\mathrm{k}^{*}$ is stable. To see this, define

$$
\varphi(k)=\frac{f_{1}\left(k_{2}-k\right)}{k\left(k_{2}-k_{1}\right)}
$$

where $k$ satisfies

$$
k=\frac{A_{1} \lambda_{1} k_{1}+A_{2} \lambda_{2} k_{2}}{A_{1} \lambda_{1}+A_{2} \lambda_{2}}=\psi(\omega) .
$$

Substituting (3.3) in (4.5), we get:

$$
\varphi(k)=\frac{f_{1} A_{1} \lambda_{1}}{A_{1} \lambda_{1} k_{1}+A_{2} \lambda_{2} k_{2}}
$$

All the variables on the right-hand side of $(4.6)$ are functions of $w$ and since $w$ has a unique positive relation with $k$, all of them are functions of $k$. In particular, we need to know how demand elasticities are related to $k$.

We know from Lemmas $3(a)$ and $4(a)$ and equations (2.18) and (2.19) that for any given $k, \epsilon_{i}$ is uniquely related to $w$. Then given that $\mathrm{d} w / \mathrm{d} k>0$ from (3.7), the following expressions concerning the sign of $d \varepsilon_{i} / d k$ can be obtained: 
(4.7) $\quad \frac{\mathrm{d} \epsilon_{1}}{\mathrm{dk}}=\frac{\partial \varepsilon_{1}}{\partial \omega} \cdot \frac{\mathrm{d} \omega}{\mathrm{dk}} \lesseqgtr 0$, if $k_{2} \gtrless \mathrm{k}_{1}$

and

(4.8) $\quad \frac{\mathrm{d} \epsilon_{2}}{\mathrm{dk}}=\frac{\partial \epsilon_{2}}{\partial \omega} \cdot \frac{\mathrm{d} \omega}{\mathrm{dk}} \gtrless 0$, if $\mathrm{k}_{2} \gtrless \mathrm{k}_{1}$.

Since $d \omega / d k>0, d \epsilon_{i} / d k$ has the same sign as $\partial \epsilon_{i} / \partial \omega$ as described by (2.18) and (2.19). Differentiating $(4.6)$ with respect to $k$, we have: ${ }^{12}$

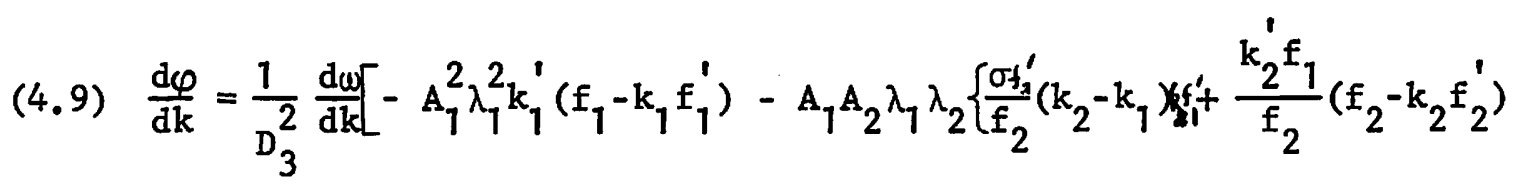

$$
\begin{aligned}
& \left.\left.+\sigma f_{1} k_{2}\left(\frac{1}{\varepsilon_{2}\left(\epsilon_{2}-1\right)} \frac{\partial \epsilon_{2}}{\partial \omega}-\frac{1}{\epsilon_{1}\left(\epsilon_{1-1}\right)} \frac{\partial \epsilon_{1}}{\partial \omega}\right)\right\}\right]
\end{aligned}
$$

where $A_{1}, A_{2}, \lambda_{1}, \lambda_{2}$ have been defined before and are all positive, and $D_{3}^{2}=\left(A_{1} \lambda_{1} k_{1}+A_{2} \lambda_{2} k_{2}\right)^{2}>0$.

Now the necessary and sufficient condition for the balanced growth path to be stable and uniquely determined is that $\mathrm{d} \varphi / \mathrm{dk}<0 . \quad$ Since $\mathrm{d} \omega / \mathrm{dk}>0$, $\mathrm{d} \varphi / \mathrm{dk}<0$ only if the expression within the brackets is negative. A careful examination of (4.9) reveals that the expression within the brackets is necessarily negative if the capital-intensity condition is satisfied, i.e., if $k_{2}>k_{1}$. Because if $k_{2}>k_{1}$, then from (2.18) and (2.19), $\partial \epsilon_{2} / \partial \omega>0$ and $\partial \epsilon_{1} / \partial \omega<0$. The following theorem is then immediate.

Theorem 3: If the capital-intensity condition is satisfied, the balancedcapital/labor ratio, $\mathrm{k}^{*}$, is uniquely determined and the balanced growth path corresponding to $\mathrm{k}^{*}$ is stable. That is to say, along any path of growth equilibrium, the capital/labor ratio, $k$, asymptotically approaches the uniquely determined balanced capital/labor ratio.

The stability of the growth process is described in Figure 5, where k* is uniquely determined by $(\eta+\mu)$, and the balanced growth path is achieved at point $E$. 
In the balanced growth path, capital and labor grow at the same rate; national income and the two outputs also grow at this rate; however, the wage/rental ratio, factor rewards, prices, per capita income and the rates of monopoly profit remain constant over time.

In the general case where the capital-intensity condition is not satisfied, the balanced capital/labor ratio may still be uniquely determined if $\mathrm{d} \varphi / \mathrm{dk}<0$ in spite of $k_{2}<k_{1}$, in which case the balanced growth path will be stable. However, the growth model may also be unstable as shown in Figure 6 . This may be proved as follows.

In view of the Arrow-Block-Hurwicz theorem, it is sufficient for the growth path described by (1.11) to be globally stable if the right hand side of (4.6) tends to infinity as $k$ approaches zero and to zero as $k$ approaches infinity. However, $k$ lies between $k_{2}$ and $k_{1}$, both of which tend to infinity (or zero) as $k$ approaches infinity (or zero). In view of (2.14)-(2.16), it is sufficient to show that

$$
\begin{array}{lc}
\lim \varphi(k)=\infty & \text { and } \\
\omega \rightarrow 0 & \lim \varphi(k)=0,
\end{array}
$$

where $\varphi(k)$ is defined by (4.6). Alternatively, it suffices to show that (4.10) $\quad \lim \frac{1}{\varphi(k)}=0$ and $\lim \frac{1}{\varphi(k)}=\infty$.

$$
\omega \rightarrow 0 \quad \omega \rightarrow \infty
$$

From (4.6),

(4.11) $\frac{1}{\varphi(k)}=\frac{k_{1}}{f_{1}}+\frac{k_{2}}{f_{1}} \frac{A_{2}}{A_{1}} \cdot \frac{\lambda_{2}}{\lambda_{1}}$.

From Inada conditions (2.14) - (2.15),

$$
\begin{aligned}
& \lim \frac{k_{1}}{f_{1}}=0 \text { and } \lim \frac{k_{1}}{f_{1}}=\infty . \\
& \omega \rightarrow 0 \quad \omega \rightarrow \infty
\end{aligned}
$$



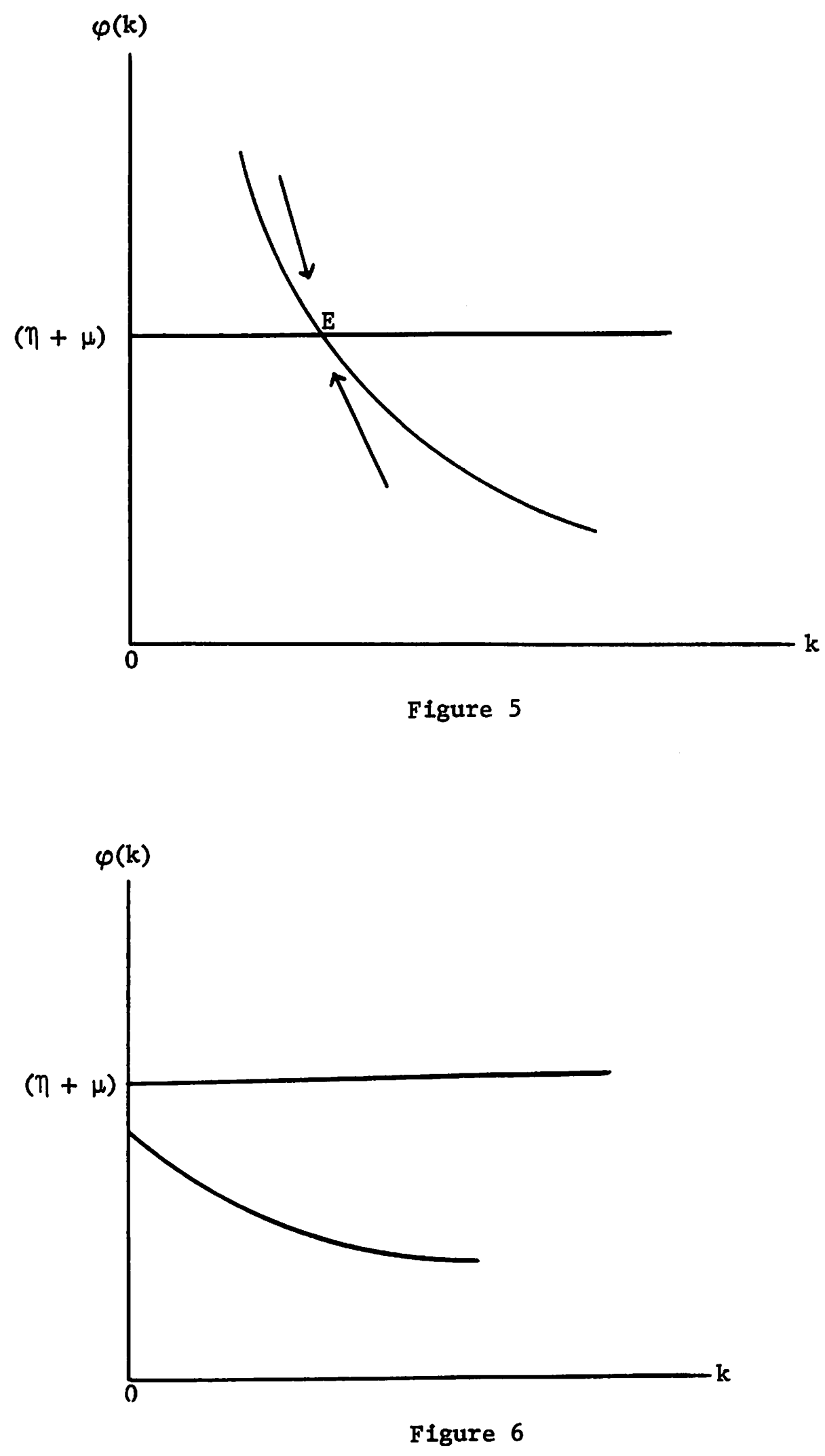
Now $\left(\lambda_{2} / \lambda_{1}\right)=\left(1-1 / \epsilon_{2}\right)^{\sigma} /\left(1-1 / \epsilon_{1}\right)^{\sigma}$. From Lemma (3) we can show that when $\mathrm{k}_{2}<\mathrm{k}_{1}$,

$$
\lim _{\omega \rightarrow 0} \frac{\left(1-1 / \varepsilon_{2}\right)^{\sigma}}{\left(1-1 / \varepsilon_{1}\right)^{\sigma}}=\infty
$$

and

$$
\lim _{\omega \rightarrow \infty} \frac{\left(1-1 / \epsilon_{2}\right)^{\sigma}}{\left(1-1 / \epsilon_{1}\right)^{\sigma}}=0
$$

A comparison of $(4.12)$ and (4.13) shows that the two terms on the right hand side of (4.11) move in the opposite directions as $\omega$ tends to zero (or infinity), so that (4.10) may not hold even if $\left(k_{2} A_{2}\right) /\left(f_{1} A_{1}\right)$, the multiplicand of $\left(\lambda_{2} / \lambda_{1}\right)$ in $(4.11)$, moves in the direction of $\left(k_{1} / f_{1}\right)$, as $w$ tends to zero (or infinity). In other words, the growth model with monopoly in both sectors may be unstable, if the capital-intensity condition does not hold, simply because, as in Figure $6, \varphi(k)$ may not tend to infinity as $k$ tends to zero. of course, it is true that when $\sigma>1$, the growth path may be unstable even under competitive conditions in both sectors, where $\left(\lambda_{2} / \lambda_{1}\right)$ reduces to unity, because here $(4.11)$ reduces to

$$
\frac{1}{\varphi(k)}=\frac{k_{1}}{f_{1}}+\frac{k_{2} A_{2}}{f_{1} A_{1}}
$$

Now

$$
\frac{k_{2} A_{2}}{f_{1} A_{1}}=\frac{k_{2}}{f_{2}} \frac{\left(f_{2}^{\prime}\right)^{\prime}}{\left.\sigma f_{1}^{\prime}\right)}=\frac{k_{2} f_{2}^{\prime}}{f_{2}} \cdot \frac{1}{\left(f_{1}^{\prime}\right)\left(f_{2}^{\prime}\right)}
$$

where from $(1.5), \frac{k_{2} f_{2}^{\prime}}{f_{2}}=\frac{k_{2}}{k_{2}+w}<1$. 
Now

$$
\begin{aligned}
& \lim _{\omega \rightarrow 0} \frac{1}{\left(f_{1}^{\prime}\right)\left(f_{2}^{\prime}\right)}=0 \text {, and } \lim \frac{1}{\left(f_{1}^{\prime}\right)\left(f_{2}^{\prime}\right)}=\infty \\
& \omega \rightarrow \infty
\end{aligned}
$$

only if $0 \leq \sigma \leq 1$, so that $(4.16)$ and (4.12) do not conflict only if $\sigma$ lies between, or is at most equal to, zero and unity. If $\sigma>1$, we confront the same problem as before, namely, the two terms on the right hand side of (4.15) move in the opposite directions as $w$ varies between zero and infinity, so that $(4.10)$ may not hold. In other words, when $\sigma>1$, even with perfect competition, the growth path may be unstable, if the capital-intensity condition is not satisfied. However, the interesting point is that when the capital-intensity condition is violated, the growth path becomes more unstable than before, or even if the growth path was stable in the absence of monopoly (in spite of $\sigma>1$ ), it may become unstable in its presence. The reason is clear from (4.9), where we require $\mathrm{d} \varphi / \mathrm{dk}<0$ for the growth model to be stable. In the absence of monopoly, $\partial \epsilon_{i} \partial \omega=0$, and suppose that $d \varphi / d k<0$ even if $k_{2}<k_{1}$, so that the growth path is stable. With the introduction of monopoly, $\partial \varepsilon_{2} / \partial w<0$ and $\partial \varepsilon_{2} / \partial w>0$, if $k_{2}<k_{1}$. This means that the presence of monopoly adds another positive factor in (4.9), apart from $-\sigma\left(k_{2}-k_{1}\right)$, when $k_{2}<k_{1}$. Hence $d \varphi / d k$ may be positive in the presence of monopoly even though it is negative in its absence, in spite of $k_{2}<k_{1}$. In other words, when the capital-intensity condition is not satisfied, the presence of monopoly in the two-sector growth model is destabilizing.

By the same token, the influence of monopoly on the growth path is stabilizing in the case where the capital-intensity condition is valid.

\section{Conclusions}

In the foregoing analysis, using a two-sector, two factor model where product markets are characterized by "pure" monopoly, we have derived conditions 
for the existence, uniqueness and the stability of equilibrium in the short run as well as in the long run. It is well known from the traditional partial equilibrium analysis of monopoly that the price elasticity of demand must exceed unity for an equilibrium to exist. This result is also valid in a general equilibrium analysis of monopoly, and, when translated in terms of a two-sector growth model, it implies that the propensity to save is variable. Thus a variable propensity to save is shown to be a necessary condition for the monopoly equilibrium to exist at any point of time. Given this condition, the momentary (or short run) equilibrium is uniquely determined. However, in the long run, we require additional conditions for the growth model to be stable. Specifically, the balanced growth path is stable under monopoly if the capital-intensity condition is satisfied. Otherwise, the growth path may be unstable. It may be noted here that this result is in conformity with Inada's [6] result derived under the assumption of perfect competition in product markets. The interesting point, however, is that the presence of monopoly contributes to stability when the capital-intensity condition is satisfied in the sense that the economic system, once off the balanced growth path, approaches the latter at a faster rate under monopoly than under perfect competition. On the other hand, if the capital-intensity condition is violated, the presence of monopoly contributes to instability. 


\section{Footnotes}

* I am grateful to J. R. Melvin and R. W. Warne for giving me the privilege of consulting their unpublished paper [7], which extends the traditional trade theory to the case of monopoly. In fact, the stimulus to this paper came from reading their paper. Thanks are also due to V. S. Rao for helpful discussions. None of them, however, are responsible for any errors.

1'See, for example, Shinkai [10], Uzawa [14] [15], Drandakis [4], She11 [9], Sato [8], Takayama [12] [13], Batra [1] and Batra and Singh [2].

2 Freedom of entry may be restricted by assuming that either all production takes place under government franchise, patent laws protect the monopolist, or the monopolist has such an efficient technology that no other producer can possibly compete with him.

3 The assumption concerning ownership of the capital stock by the monopolist is actually unnecessary and does not play any role in the stability analysis of the mode1. We have made this assumption just to obtain an elegant expression for the rate of monopoly profit $\left(\pi_{i}\right)$, and, of course, in most cases, this may be true in reality.

${ }^{4}$ The CES utility function in the context of the two-sector growth model has been previously used by Inada [6]. However, in the subsequent analysis we will show that, like Inada's results, our results are valid even if the homogeneous utility function does not have constant elasticity of substitution.

${ }^{5}$ This name is given by Solow [11] in the competitive case.

6 These demand functions and the corresponding price elasticities are obtained in the Appendix.

7 Remember that $\sigma=1 /(1+\beta)$.

${ }^{8}$ See Chipman [3, pp. 57-9] and Melvin and Warne [7].

${ }^{9}$ Equation (3.4) is derived in the Appendix.

${ }^{10}$ See the Appendix for the derivation of $(3.5)$

${ }^{11}$ That $A>0$ is shown in the Appendix.

${ }^{12}$ Equation (4.9) is derived in the Appendix. 


\section{References}

1. Batra, R. "Hicks and Harrod-Neutral Technical Progress and the Relative Stability of a Two-Sector Growth Model with Fixed Coefficients," Journal of Political Economy, Jan./Feb. 1970, 84-96.

2. Batra, R. and R. Singh, "Intermediate Products and the Two-Sector Growth Model," Paper presented at the Econometric Society Meetings, Detroit, December 1970.

3. Chipman, J. S., "A Survey of the Theory of International Trade: Part 3, the Modern Theory," Econometrica, January 1966.

4. Drandakis, E. M., "Factor Substitution in the Two-Sector Growth Mode1," Review of Economic Studies, October 1963, 217-28.

5. Inada, K., "On a Two-Sector Model of Economic Growth: Comments and a Generalization," Review of Economic Studies, April 1964, 119-27.

6. Inada, K., "On the Stability of Growth Equilibria in Two-Sector Models," Review of Economic Studies, April 1964, 127-42.

7. Melvin, J. R. and R. W. Warne, "Monopoly and the Theory of International Trade," Research Report 7032, Department of Eccnomics, University of Western Ontario, London, Ontario.

8. Sato, R., "Stability Conditions in Two-Sector Models of Economic Growth," Journal of Economic Theory, June 1969, 107-17.

9. Shel1, K., "Comparative Statics for Two-Sector Mode1," Metronomica, MayAugust 1960, 118-24.

10. Shinkai, Y., "On Equilibrium Growth of Capital and Labor," International Economic Review, May 1960, 107-11.

11. Solow, R. M., "Note on Uzawa's Two-Sector Model of Economic Growth," Review of Economic Studies, October 1961, 48-50.

12. Takayama, A., "On a Two-Sector Model of Economic Growth: A Comparative Statics Analysis," Review of Economic Studies, June 1963, 95-104.

13. Takayama, A., "On a Two-Sector Model of Economic Growth with Technical Progress: A Comparative Statics Analysis," Review of Economic Studies, July 1965, 251-62.

14. Uzawa, H., "On a Two-Sector Model of Economic Growth," Review of Economic Studies, October 1961, 40-7.

15. Uzawa, H., "On a Two-Sector Model of Economic Growth, II" Review of Economic Studies, June 1963, 105-18. 


\section{Append ix}

Some of the equations presented in the text without proof will now be derived. Consider a utility function with a constant elasticity of substitution, $\sigma$, where $\sigma=1 /(1+\beta),-1<\beta<0$. With two sectors in the economy producing two goods, $y_{1}$ and $y_{2}$, the utility function can be represented as

(A.1) $U=\left(a y_{1}^{-\beta}+b y_{2}^{-\beta}\right)^{-1 / \beta}$

where $a / b$ is assumed to be unity for the sake of simplicity of calculations. Given the constraint that $y=p_{1} y_{1}+p_{2} y_{2}$, we form the Lagrangian function:

(A.2) $z=\left(a y_{1}^{-\beta}+b y_{2}^{-\beta}\right)^{-1 / \beta}+\alpha\left(y-p_{1} y_{1}-p_{2} y_{2}\right)$

Maximizing, we obtain

(A.3) $\frac{\partial z}{\partial y_{1}}=-\frac{1}{\beta}\left(a y_{1}^{-\beta}+b_{y_{2}^{-\beta}}^{-1 / \beta \sigma}\left(-a \beta y_{1}^{-1 / \sigma}-p_{1} \alpha=0\right.\right.$,

(A.4) $\frac{\partial z}{\partial y_{2}}=-\frac{1}{\beta}\left(a y_{1}^{-\beta}+b_{2}^{-\beta}\right)^{-1 / \beta \sigma}\left(-b \beta y^{-1 / \sigma}\right)-p_{2} \alpha=0$,

(A.5) $\frac{\partial z}{\partial \alpha}=y-p_{1} y_{1}-p_{2} y_{2}=0$.

From (A.3) and (A.4) we have:
a $y_{1}^{-1 / \sigma}\left(a y_{1}^{-\beta}+\mathrm{b} \mathrm{y}_{2}^{-\beta}\right)^{-1 / \beta \sigma}=\mathrm{p}_{1} \alpha$,
$\mathrm{b} \mathrm{y}_{2}^{-1 / \sigma}\left(\mathrm{a} \mathrm{y} \mathrm{y}_{1}^{-\beta}+\mathrm{b} \mathrm{y}_{2}^{-\beta}\right)^{-1 / \beta \sigma}=\mathrm{p}_{2} \alpha$ 
Dividing, using (A.5) and solving for $y_{2}$, we obtain:

(A.6) $y_{2}=\frac{y}{p_{2}\left[1+p^{\beta \sigma}\right]}$,

(A.7) $y_{1}=\frac{y}{p_{1}\left[1+p^{-\beta \sigma}\right]}$

where, as in the text, $\mathrm{p}=\frac{\mathrm{P}_{1}}{\mathrm{P}_{2}}$.

From these demand functions, the "own" price elasticities are derived

as follows:

Differentiating (A.6) partially with respect to $\mathrm{p}_{2}$, we have:

(A.8) $\frac{\partial y_{2}}{\partial p_{2}}=\frac{-y\left[1+\sigma\left(p_{2}\right)^{-\beta \sigma}\left(p_{1}\right)^{\beta \sigma}\right]}{\left[p_{2}+\left(p_{2}\right)^{\sigma}\left(p_{1}\right)^{\beta \sigma}\right]^{2}}$,

whence

$$
-\epsilon_{2}=\frac{\partial y_{2}}{\partial p_{2}} \cdot \frac{p_{2}}{y_{2}}=-\frac{p_{2}\left[1+\sigma\left(p_{2}\right)^{-\beta \sigma}\left(p_{1}\right)^{\beta \sigma}\right]}{p_{2}+\left(p_{2}\right)^{\sigma}\left(p_{1}\right)^{\beta \sigma}}
$$

so that

$$
\varepsilon_{2}=\frac{1+\sigma p^{\beta \sigma}}{1+p^{\beta \sigma}} .
$$

Similarly,

$$
\epsilon_{1}=\frac{1+\sigma p^{-\beta \sigma}}{1+p^{-\beta \sigma}} .
$$

It may be observed that in the derivation of demand elasticities, we have assumed that money national income, $y$, is constant at all points on the transformation 
curve. The validity of this procedure stems from the fact that for any productprice ratio, individual prices can always be so adjusted as to keep income unchanged. The elasticities will be unaltered, because they depend only on the price ratio.

So far we have derived some of the equations presented in Section II of the text. Now we turn to some of the equations presented without proof in Section III. From equation (3.3),

(3.3) $k=\frac{A_{1} \lambda_{1} k_{1}+A_{2} \lambda_{2} k_{2}}{A_{1} \lambda_{1}+A_{2} \lambda_{2}}$

where $A_{1}=f_{2} f_{1}^{\prime \sigma}, A_{2}=f_{1} f_{2}^{\prime \sigma}$ and $\lambda_{i}=\left(1-1 / \epsilon_{i}\right)^{\sigma}, \quad i=1,2$.

Differentiating (3.3) with respect to $\omega$ we have:

$$
\text { (A.9) } \begin{aligned}
\frac{\mathrm{d} k}{\mathrm{~d} w}=\frac{1}{\mathrm{D}_{1}^{2}}\left[\left(\mathrm{~A}_{1} \lambda_{1}\right.\right. & \left.+\mathrm{A}_{2} \lambda_{2}\right)\left(\mathrm{A}_{1} \lambda_{1} \mathrm{k}_{1}^{\prime}+\mathrm{k}_{1} \lambda_{1} \mathrm{~A}_{1}^{\prime}+\mathrm{A}_{1} \mathrm{k}_{1} \lambda_{1}^{\prime}+\mathrm{A}_{2} \lambda_{2} \mathrm{k}_{2}^{\prime}+\lambda_{2} \mathrm{k}_{2} \mathrm{~A}_{2}^{\prime}+\mathrm{A}_{2} \mathrm{k}_{2} \lambda_{2}^{\prime}\right) \\
& \left.-\left(\mathrm{A}_{1} \lambda_{1} \mathrm{k}_{1}+\mathrm{A}_{2} \lambda_{2} \mathrm{k}_{2}\right)\left(\lambda_{1} \mathrm{~A}_{1}^{\prime}+\mathrm{A}_{1} \lambda_{1}^{\prime}+\lambda_{2} \mathrm{~A}_{2}^{\prime}+\mathrm{A}_{2} \lambda_{2}^{\prime}\right)\right]
\end{aligned}
$$

where $D_{1}^{2}=\left(A_{1} \lambda_{1}+A_{2} \lambda_{2}\right)^{2}$.

Simplifying, we get equation (3.4) in the text:

(3.4) $\frac{\mathrm{dk}}{\mathrm{d} \omega}=\frac{1}{\mathrm{D}_{1}^{2}}\left[\left(\mathrm{~A}_{1}^{2} \lambda_{1}^{2} \mathrm{k}_{1}^{\prime}+\mathrm{A}_{2}^{2} \lambda_{2}^{2} \mathrm{k}_{2}^{\prime}\right)+\lambda_{1} \lambda_{2} \mathrm{~A}+\mathrm{A}_{1} \mathrm{~A}_{2}\left(\mathrm{k}_{2}-\mathrm{k}_{1}\right)\left(\lambda_{1} \lambda_{2}^{\prime}-\lambda_{2} \lambda_{1}^{\prime}\right)\right]$.

where

$$
A=A_{1} k_{2} A_{2}^{\prime}+A_{1} A_{2} k_{2}^{\prime}+A_{2} k_{1} A_{1}^{\prime}+A_{1} A_{2} k_{1}^{\prime}-A_{1} k_{1} A_{2}^{\prime}-A_{2} k_{2} A_{1}^{\prime} .
$$

Now differentiating $\lambda_{1}=\left(1-\frac{1}{\epsilon_{1}}\right)^{\sigma}$ with respect to $\omega$ we have

(A.10) $\lambda_{1}^{\prime}=\frac{\sigma\left(1-1 / \epsilon_{1}\right)^{\sigma-1}}{\epsilon_{1}{ }^{2}} \frac{\mathrm{d} \epsilon_{1}}{\mathrm{dx}} \frac{\mathrm{dx}}{\mathrm{d} \omega}=\frac{\sigma \lambda_{1}}{\epsilon_{1}\left(\epsilon_{1}-1\right)} \frac{\mathrm{d} \epsilon_{1}}{\mathrm{dx}} \cdot \frac{\mathrm{dx}}{\mathrm{d} \omega}$.

Substituting $\epsilon_{1}$ from (2.7) and $d \epsilon_{1} / d x$ from (2.9), we obtain: 
$-37-$

$$
\lambda_{1}^{\prime}=-\frac{\sigma \lambda_{1}\left(1+x^{-\beta}\right)^{2}}{\left(1+\sigma x^{-\beta}\right)(1-\sigma) x^{-\beta}} \cdot \frac{\beta(1-\sigma) x^{-(1+\beta)}}{\left(1+x^{-\beta}\right)^{2}} \frac{d x}{d \omega}=-\frac{\beta \sigma \lambda_{1} x^{-(1+\beta)}}{\left(1+\sigma x^{-\beta}\right)} \frac{d x}{d \omega}
$$

Similarly, from $\lambda_{2}=\left(1-1 / \epsilon_{2}\right)^{\sigma}$, we can derive:

$$
\lambda_{2}^{\prime}=\frac{\sigma \lambda_{2} \beta}{x\left(1+\sigma x^{\beta}\right)} \frac{d x}{d \omega}
$$

Then utilizing (A.11), (A.12) and $\lambda_{i}$ gives us equation (3.5) in the text.

We now show that

$$
A=A_{1} k_{2} A_{2}^{\prime}+A_{1} A_{2} k_{2}^{\prime}+A_{2} k_{1} A_{1}^{\prime}+A_{1} A_{2} k_{1}^{\prime}-A_{1} k_{1} A_{2}^{\prime}-A_{2} k_{2} A_{1}^{\prime},
$$

utilized in (3.4) is positive.

Now

$$
A_{1}^{\prime}=\sigma\left(f_{1}^{\prime}\right)^{\sigma-1} f_{1}^{\prime \prime} k_{1}^{\prime} f_{2}+\left(f_{1}^{\prime}\right)^{\sigma} f_{2}^{\prime} k_{2}^{\prime}
$$

and

$$
A_{2}^{\prime}=\sigma\left(f_{2}^{\prime}\right)^{\sigma-1} f_{2}^{\prime \prime} k_{2}^{\prime} f_{1}+\left(f_{2}^{\prime}\right)^{\sigma} f_{1}^{\prime} k_{1}^{\prime}
$$

Since

$$
k_{i}^{\prime}=\frac{-\left(f_{i}^{\prime}\right)^{2}}{f_{i}^{\prime \prime} f_{i}^{\prime \prime}} \quad(i=1,2)
$$

we have,

$$
A_{1}^{\prime}=\frac{-\sigma\left(f_{1}^{\prime}\right)^{\sigma+1} f_{2}}{f_{1}}+\left(f_{1}^{\prime}\right)^{\sigma} f_{2}^{\prime} k_{2}^{\prime}
$$

(A.14) $\quad A_{2}^{\prime}=-\frac{\sigma\left(f_{2}^{\prime}\right)^{\sigma+1} f_{1}}{f_{2}}+\left(f_{2}^{\prime}\right)^{\sigma} f_{1}^{\prime} k_{1}^{\prime}$.

Then

$$
\begin{aligned}
A=-\sigma\left(f_{1}^{\prime}\right)^{\sigma} & \left(f_{2}^{\prime}\right)^{\sigma+1} f_{1}\left(k_{2}-k_{1}\right)+\left(f_{2}^{\prime}\right)^{\sigma} f_{2} f_{1}^{\prime} k_{1}^{\prime}\left(k_{2}-k_{1}\right)+\left(f_{1}^{\prime}\right)^{\sigma}\left(f_{2}^{\prime}\right)^{\sigma} f_{2} f_{1} k_{2}^{\prime} \\
& +\left(f_{1}^{\prime}\right)^{\sigma}\left(f_{2}^{\prime}\right)^{\sigma} f_{2} f_{1} k_{1}^{\prime}+\sigma\left(f_{2}^{\prime}\right)^{\sigma}\left(f_{1}^{\prime}\right)^{\sigma+1} f_{2}\left(k_{2}-k_{1}\right)-\left(f_{2}^{\prime}\right)^{\sigma}\left(f_{1}^{\prime}\right)^{\sigma} f_{2}^{\prime} k_{2}^{\prime} f_{1}\left(k_{2}-k_{1}\right)
\end{aligned}
$$


$-38-$

Combining some terms we get,

$$
\begin{aligned}
A=-\sigma\left(f_{1}^{\prime}\right) & \left(f_{2}^{\prime}\right)^{\sigma}\left(k_{2}-k_{1}\right)\left(f_{2}^{\prime} f_{1}-f_{1}^{\prime} f_{2}\right)+\left(f_{2}^{\prime}\right)^{\sigma}\left(f_{1}^{\prime}\right)^{\sigma} f_{2} f_{1}^{\prime} k_{1}^{\prime} k_{2}+\left(f_{1}^{\prime}\right)^{\sigma}\left(f_{2}^{\prime}\right)^{\sigma} f_{2} k_{1}^{\prime}\left(f_{1}-k_{1} f_{1}^{\prime}\right) \\
& +\left(f_{2}^{\prime}\right)^{\sigma}\left(f_{1}^{\prime}\right) f_{1} f_{2}^{\prime}\left(f_{2}-k_{2} f_{2}^{\prime}\right)+\left(f_{2}^{\prime}\right)^{\sigma}\left(f_{1}^{\prime}\right)^{\sigma} f_{2}^{\prime} k_{2}^{\prime} f_{1} k_{1}
\end{aligned}
$$

Now from $(1.5)$,

$$
f_{2}^{\prime} f_{1}-f_{1}^{\prime} f_{2}=f_{2}^{\prime} f_{1}^{\prime}\left(\frac{f_{1}}{f_{1}^{\prime}}-\frac{f_{2}}{f_{2}^{\prime}}\right)=-f_{2}^{\prime} f_{1}^{\prime}\left(k_{2}-k_{1}\right) \text {, }
$$

and

$$
f_{i}^{\prime} w=f_{i}-k_{i} f_{i}^{\prime},
$$

so that

$$
\begin{aligned}
A=\sigma\left(f_{1}^{\prime}\right)^{\sigma+1}\left(f_{2}^{\prime}\right)^{\sigma+1}\left(k_{2}-k_{1}\right)^{2} & +\left(f_{1}^{\prime}\right)^{\sigma}\left(f_{2}^{\prime}\right)^{\sigma} f_{2} k_{1}^{\prime} f_{1}^{\prime}\left(k_{2}+w\right) \\
& +\left(f_{1}^{\prime}\right)^{\sigma}\left(f_{2}^{\prime}\right)^{\sigma} f_{1} k_{2}^{\prime} f_{2}^{\prime}\left(k_{1}+w\right) .
\end{aligned}
$$

It may be observed from (A.15) that all three terms in its right-hand side are positive. Therefore $A>0$.

There still remains equation (4.9) to be derived. Equation (4.6) is (4.6) $\varphi(k)=\frac{f_{1} A_{1} \lambda_{1}}{A_{1} \lambda_{1} k_{1}+A_{2} \lambda_{2} k_{2}}$.

Differentiating (4.6) with respect to $k$, we obtain:

(A.16) $\frac{d \varphi}{d k}=\frac{1}{D_{3}^{2}}\left[\left(A_{1} \lambda_{1} k_{1}+A_{2} \lambda_{2} k_{2}\right)\left(A_{1} \lambda_{1} f_{1}^{\prime} k_{1}^{\prime}+f_{1} \lambda_{1} A_{1}^{\prime}+f_{1} A_{1} \lambda_{1}^{\prime}\right)\right.$

$$
\left.-\mathrm{f}_{1} \mathrm{~A}_{1} \lambda_{1}\left(\mathrm{~A}_{1} \mathrm{k}_{1} \lambda_{1}^{\prime}+\mathrm{A}_{1} \lambda_{1} \mathrm{k}_{1}^{\prime}+\mathrm{k}_{1} \lambda_{1} \mathrm{~A}_{1}^{\prime}+\mathrm{A}_{2} \mathrm{k}_{2} \lambda_{2}^{\prime}+\mathrm{A}_{2} \lambda_{2} \mathrm{k}_{2}^{\prime}+\mathrm{k}_{2} \lambda_{2} \mathrm{~A}_{2}^{\prime}\right)\right] \frac{\mathrm{d} \omega}{\mathrm{dk}}
$$

where $D_{3}^{2}=\left(A_{1} \lambda_{1} k_{1}+A_{2} \lambda_{2} k_{2}\right)^{2}$. 
-39-

Simplifying (A.16) we get

(A. 17) $\frac{\mathrm{d} \varphi}{\mathrm{dk}}=\frac{1}{\mathrm{D}_{3}^{2}}\left[-\mathrm{A}_{1}^{2} \lambda_{1}^{2} \mathrm{k}_{1}^{\prime}\left(\mathrm{f}_{1}-\mathrm{k}_{1} \mathrm{f}_{1}^{\prime}\right)+\lambda_{1} \lambda_{2} \mathrm{k}_{2} \mathrm{f}_{1}\left(\mathrm{~A}_{2} \mathrm{~A}_{1}^{\prime}-\mathrm{A}_{1} \mathrm{~A}_{2}^{\prime}\right)\right.$

$$
\left.+A_{1} A_{2} k_{2} f_{1}\left(\lambda_{2} \lambda_{1}^{\prime}-\lambda_{7} \lambda_{2}^{\prime}\right)+\lambda_{1} \lambda_{2} A_{1} A_{2}\left(k_{2} f_{1}^{\prime} k_{1}^{\prime}-f_{1} k_{2}^{\prime}\right)\right] \frac{d \omega}{d k}
$$

Here it can be shown that now

(A. 18) $\lambda_{2} \lambda_{1}^{\prime}-\lambda_{1} \lambda_{2}^{\prime}=\frac{\sigma \lambda_{1} \lambda_{2}}{\epsilon_{1}\left(\epsilon_{1}-1\right)} \frac{\partial \epsilon_{1}}{\partial \omega}-\frac{\sigma \lambda_{1} \lambda_{2}}{\epsilon_{2}{ }^{\left(\varepsilon_{2}-1\right)}} \frac{\partial \varepsilon_{2}}{\partial \omega}$.

Then substituting (A.18), (A.13) and (A.14) in (A.17), we get equation (4.9) derived in the text. 